http://jmscr.igmpublication.org/home/ ISSN (e)-2347-176x ISSN (p) 2455-0450

crossref DOI: https://dx.doi.org/10.18535/jmscr/v7i9.81

\author{
Journal Of Medical Science And Clinical Research \\ IGM Publication \\ An Official Publication of IGM Publication
}

\title{
Silicosis in a Flourmill Worker: A Case Report
}

\author{
Authors \\ Dr Parminder Pal Singh ${ }^{1}$, Dr Vicky Bakshi ${ }^{2}$, Dr Kulbir Singh ${ }^{3}$, Dr Karan Sharma \\ ${ }^{1}$ Senior Resident, Department of Internal Medicine, G.M.C. Patiala \\ ${ }^{2,4}$ Junior Resident, Department of Pulmonary Medicine, G.M.C. Patiala \\ ${ }^{3}$ Associate Professor, Department of Pulmonary Medicine, G.M.C. Patiala
}

\begin{abstract}
We herein report a case of silicosis in a 60 years old male worked in a Flourmill for 38 years, and started grinding flour 6 years back. Silicosis is a form of pneumoconiosis caused by inhalation of crystalline silica dust reported in silica mill workers, slate pen workers, miners. In India, silicosis has been made a notifiable disease under the Factories Act 1948 and Mines act 1952. Few case reports in the past have referred to silicosis in flourmill workers in India. However, its association with flour mill workers has not yet been established. This case report is an evidence that silicosis can occur in flourmill workers too, especially in those who are involved in grinding process. Flourmills in India commonly use silicacontaining grinding stones that require regular chiseling.

Keywords: Flourmill; Silicosis; Occupational lung disease.
\end{abstract}

\section{Introduction}

Silicosis is a form of pneumoconiosis caused by inhalation of crystalline silica dust reported in silica mill workers, slate pen workers, miners. Silicosis is a preventable disease and eliciting appropriate occupational exposure history is essential in clinching the diagnosis. Primary prevention in the form of dust control measures at work place and secondary measures such as use of protective gear including masks and respirators by the workers can dramatically reduce the incidence of silicosis. ${ }^{1}$

Flour is fine powder made from cereals or other starchy food sources. In India, flour production is predominantly in the small scale industry (unorganized sector) and milling is accomplished by grinding grain between stones and a steel wheel. The use of the "Agra" (80\% silica content) and the buff stone ( $81 \%$ silica) for grinding and regular chiseling by the workers in order to maintain the rough texture of the surface leads to silica dust exposure. In India, silicosis has been made a notifiable disease under the Factories Act 1948 and Mines act 1952. Few case reports in the past have referred to silicosis in flourmill workers in India. ${ }^{2}$ However, its association with flour mill workers has not yet been established.

This is yet another case report of silicosis in a flourmill worker in Patiala, Punjab

\section{Case Report}

A 60 years old male patient, resident of Village Chaura, District Patiala presented to the outpatient department with chief presenting complaints of Breathlessness on exertion and productive cough increased for 4 months, Loss of 


\section{JMSCR Vol||07||Issue||09||Page 472-475||September}

appetite for 10 days and fever which was undocumented for a period of 5 days. Past history and familial history was unremarkable. No history of any addiction was there. Patient worked in a Flourmill for 38 years, and started grinding flour 6 years back. He used to grind for 5 hours every day and started having symptoms after 1 year of grinding itself, which increased in the last 4 months.

General physical examination revealed pallor and clubbing (grade 3) in all fingers. Chest examination was unremarkable except for Velcro crepitations present bilaterally in interscapular, infrascapular, inframammary and infraaxillary areas.

Chest X Ray done 4 mnths back did not reveal any abnormality except for right hilar prominence, Chest X Ray Posterio-anterior view was repeated and new chest $X$ ray revealed bilateral diffuse nodular opacities in all zones.

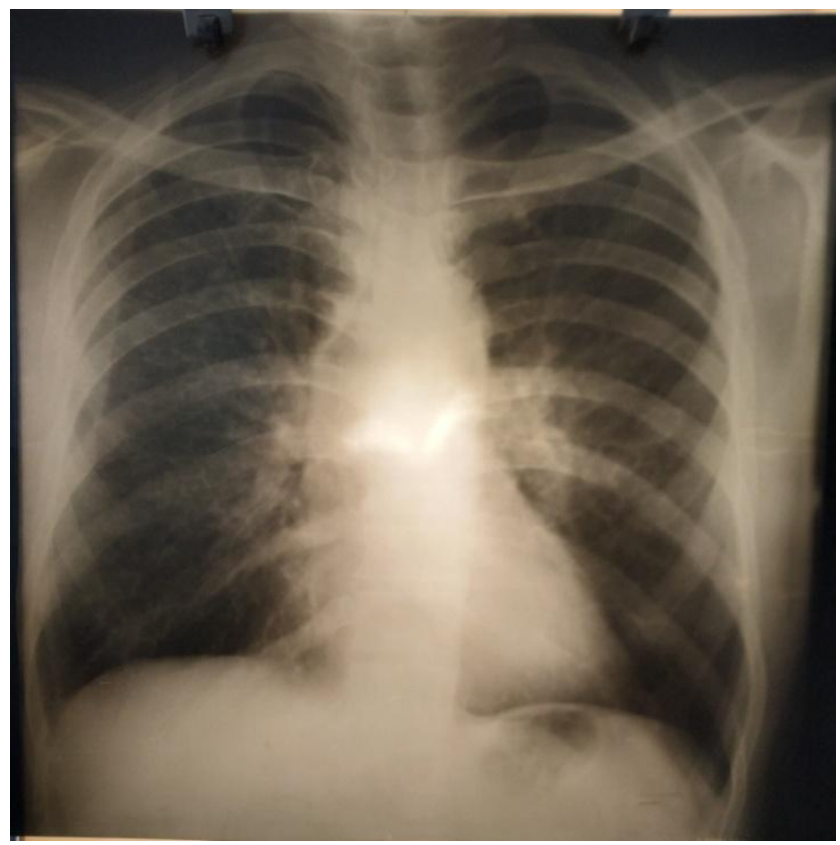

Picture 1: Chest X Ray PA view of patient 4 months old showing no abnormalities except for right hilar prominence

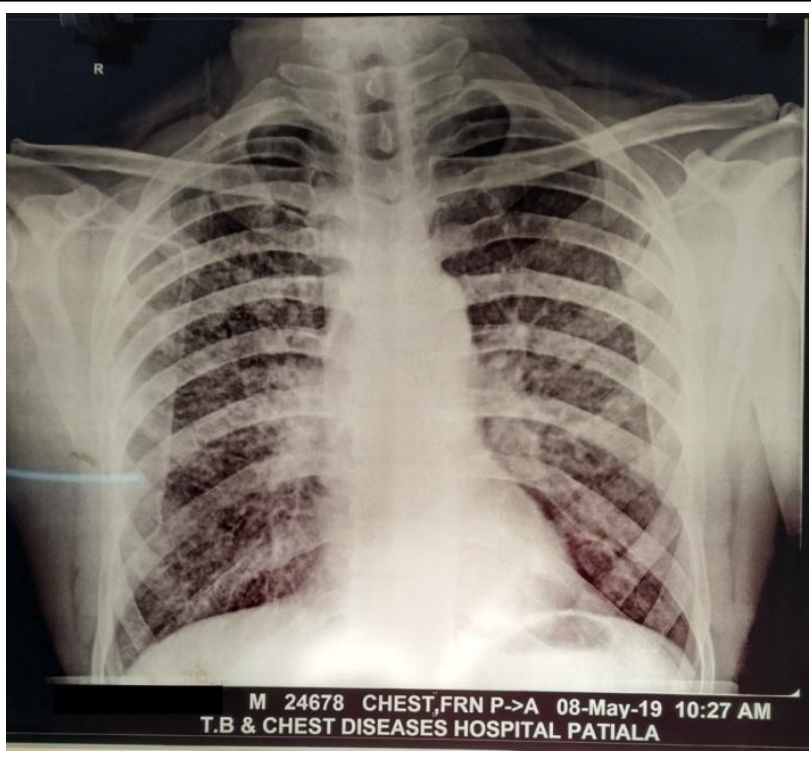

Picture 2: Recent Chest $X$ Ray of the same individual showing bilateral fine nodular opacities in all zones

Milliary tuberculosis was required to be ruled out keeping in mind the high prevalence of disease in Indian settings. Sputum for AFB came out as negative, Ultrasound of whole abdomen was normal and fundus examination did not reveal any signs suggestive of disseminated disease. Sputum for CBNAAT also did not detect mycobacterium.

Patient was advised High resolution Computed Tomography (HRCT) scan. HRCT revealed numerous subcentrimeter sized well demarcated soft tissue nodules in both lungs, predominantly in central part and sparing basal segment of both lower lobes. Multiple enlarged lymph nodes with calcification were also seen in mediastinum.

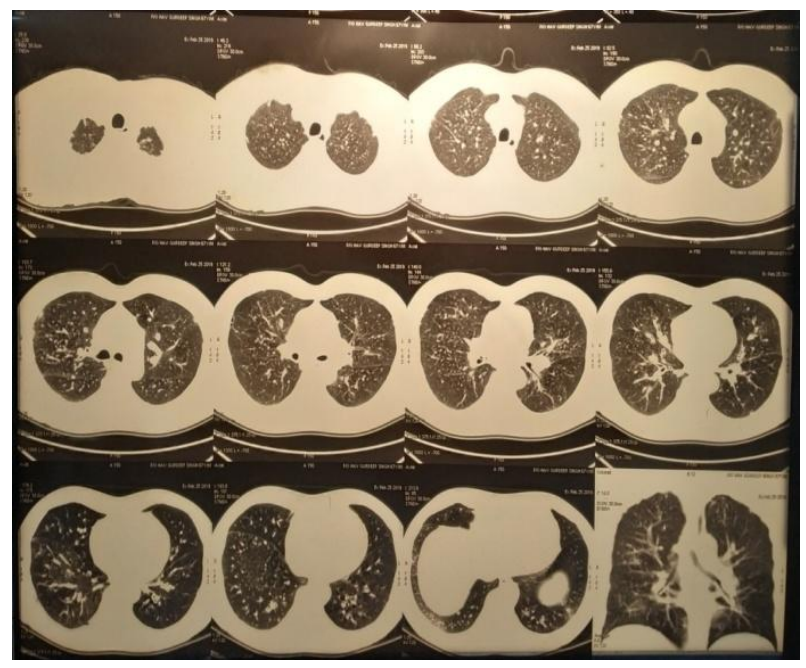

Picture 3: A few sections of HRCT of the patient revealing bilateral subcentrimetric nodules 
Spirometry was also performed which showed restrictive pattern.

Hence, a diagnosis of silicosis was made based on the occupational history, chief presenting complaints and radiographic findings of the patient. Bronchoalveolar lavage and biopsy are rarely indicated in silicosis and hence were not done.

Patient was advised to change the occupation, which he refused. Hence he was advised to work in well ventilated settings and wear N95 mask to work. After 3-4 weeks, patient showed improvement symptomatically.

\section{Discussion}

Silicosis is a fibrosing disease of the lungs caused by the inhalation, retention, and pulmonary reaction to crystalline silica. ${ }^{3}$ Despite knowledge of the cause of this disorder (inhalation of dust containing respirable crystalline silica), this serious and potentially fatal occupational lung disease remains prevalent throughout the world. ${ }^{4}$ Silica, or silicon dioxide, is the predominant component of the Earth's crust. ${ }^{3}$ Silicosis frequently develops or progresses after exposures have ceased. ${ }^{5}$ In both developed and developing nations, workers in mining, quarrying, tunneling, abrasive blasting, construction, and foundry work continue to develop silicosis. ${ }^{3}$ Silicosis also continues to be diagnosed among workers from industries and work settings not previously recognized to offer a risk, reflecting the nearly ubiquitous presence of silica. ${ }^{6,7}$ This case report is an evidence that silicosis can occur in flourmill workers too, especially in those involved in grinding process. Flourmills in India commonly use silica-containing grinding stones that require regular chiseling.

Clinical and radiological features that distinguish silicosis from other fibrotic disease include occupational exposure to a substantial amount of silica, Silicotic nodule, and/or involvement of hilar lymph nodes. The classic radiographic features of simple silicosis are rounded opacities ranging in size from 1 to $10 \mathrm{~mm}$ and occurring predominantly in the upper lung zones. As the disease progresses, the opacities are also seen in the mid- and lower-lung zones. The nodules are of homogeneous density and usually bilaterally symmetrical. Egg shell calcification of the lymph nodes is strongly suggestive of silicosis. However the egg shell calcification is not specific and it may be seen with sarcoidosis, radiation-treated Hodgkin's disease, blastomycosis, scleroderma, amyloidosis or histoplasmosis.

Bronchoalveolar Lavage (BAL) study is rarely indicated. It may be undertaken when exposure history and clinical presentations are atypical. The BAL fluid of workers exposed to quartz dust will demonstrate an increased number of cells, protein and quartz in the macrophage. Lung biopsy (open or thoracoscopic) is rarely needed to establish the diagnosis. It may be indicated in some clinical settings when complications are present. This is particularly important when lung malignancy is suspected as a complication.

There is no specific treatment for silicosis and the therapy is directed largely at the complications of the disease. Corticosteroids have limited efficacy in the treatment of silicosis. Inhaled aluminum citrate powder coats silica particles retained within the lung, thereby reducing the solubility of those particles. Following the diagnosis of silicosis, it is advisable to avoid further exposure to silica-containing dusts. Prevention remains the main goal of silicosis. It comprises of medical screening and surveillance and dust control measures. The medical examination comprises of pre-employment and periodic examinations including chest radiographs, sputum examination for tubercle bacilli and spirometry. Exposure to dust can be reduced by the use of improved ventilation and local exhaust, isolation and enclosure of the sources of dust, use of wet abrasive techniques, humidification of work environment and personal protection. Masks are advocated only when other dust control measures have failed. 


\section{References}

1. The Global Occupational Health Network: Elimination of silicosis. GOHNET newsletter. Issue no.12-2007. [Last cited on 2011 Aug 3]. Available from: http://www.who.int/occupational_health.

2. Sundaram P, Kamat R, Joshi JM. Flour mill lung: A pneumoconiosis of mixed etiology. Indian J Chest Dis Allied Sci. 2002;44:199-201. [PubMed: 12206482]

3. Leung CC, Yu IT, Chen W. Silicosis. Lancet. 1997;379:2008-2018.

4. Centers for Disease Control and Prevention (CDC). Silicosis mortality, prevention, and control- United States, 1968-2002. MMWR Morb Mortal Wkly Rep. 2005;54(16);401-405.

5. Miller BG, Hagen S, Love RG, et al. Risks of silicosis in coalworkers exposed to unusual concentrations of respirable quartz. Occup Environ Med. 1998;55 (1):52-58.

6. Kramer MR, Blanc PD, Fireman E, et al. Disease resurgence among artificial stone workers.Chest. 2012;142(2):419-424.

7. Murgia N, Muzi G, Dell'Omo M, et al. An old threat in a new setting: high prevalence of silicosis among jewelry workers. Am J Ind Med. 2007;50(8):577-583. 